\title{
Genomic lineage of Salmonella enterica serotype Gallinarum
}

\author{
J. E. OLSEN, MARIANNE N. SKOV, J. P. CHRISTENSEN and M. BISGAARD
}

Department of Veterinary Microbiology, The Royal Veterinary and Agricultural University, 13 Bülowsvej, DK 1870 Frederiksberg C., Denmark

\begin{abstract}
Forty-eight strains of Salmonella enterica serotype Gallinarum of biotypes Gallinarum and Pullorum were characterised by three chromosomally based typing methods. The patterns obtained were compared with those of strains of eight other serotypes of Salmonella of $\mathrm{O}$ serogroup D. The same PvuII and PstI IS200 patterns were commonly observed among strains of both biotypes and the three $S m a I$ ribotypes of serotype Gallinarum strains differed in only one or two bands, supporting the view that members of these two biotypes are closely related. The same IS200 patterns were also commonly observed among strains of serotype Enteritidis, indicating its evolutionary relationship with serotype Gallinarum. NotI pulsed-field gel electrophoresis (PFGE) patterns divided strains into 24 types. Based on a similarity analysis, two clusters were formed. One contained the majority of biotype Gallinarum strains and two atypical strains of Pullorum; the other contained strains of biotype Pullorum and an otherwise typical strain of biotype Gallinarum. Two atypical strains of biotype Pullorum remained unclustered by PFGE analysis. The grouping of strains differed according to the typing method used, but the majority of strains within each of the biotypes Gallinarum and Pullorum were very similar by the chromosomal markers analysed.
\end{abstract}

\section{Introduction}

Strains of Salmonella enterica of the non-motile serotype Gallinarum (1, 9, 12:-:-) may be divided into biotypes Gallinarum and Pullorum which are the aetiological agents of two distinct diseases, fowl typhoid and Pullorum disease, respectively. As well as biochemical differences, which until now have formed the basis for their separation into biotypes [1-3], strains of serotype Gallinarum of biotypes Gallinarum and Pullorum differ from each other in EcoRI ribotypes [4], plasmid profiles [3], production of subfactors of antigen $\mathrm{O} 12$ [5] and in pathogenicity $[6,7]$.

All strains of serotype Gallinarum seem to be closely related. Thus a neighbour-joining tree, derived from a matrix of genetic distances based on allelic variation in 29 enzyme loci, produced one cluster containing strains of biotype Gallinarum, a second containing strains of biotype Pullorum and a third containing strains of both biotypes [8]. The same division into three groups is obtained when nucleotide differences

Received 9 Jan. 1996; accepted 19 March 1996.

Corresponding author: Dr J. E. Olsen. in the $f l \mathrm{C}$ gene are used to measure relatedness [8]. Based on the same methods, strains of serotype Gallinarum have also been shown to be closely related to the main clonal line of serotype Enteritidis and serotype Dublin is apparently a member of the same clonal line $[8,9]$

Presumptive clonal lines of serotypes Enteritidis and Dublin have been identified previously by the use of molecular fingerprinting techniques $[10,11]$. In the present study this approach was used to assess the chromosomal relatedness of strains of the two biotypes of serotype Gallinarum and to compare them with other serotypes of $\mathrm{O}$ serogroup $\mathrm{D}$. The results are discussed in the context of the presently accepted view of subgroups of serotype Gallinarum and of the close evolutionary relationships among strains of serotypes Gallinarum, Enteritidis and Dublin.

\section{Materials and methods}

Bacterial strains, media and culture conditions

A collection of 48 strains previously serotyped as Gallinarum and biotyped as Gallinarum or Pullorum [3,4] was investigated; 10 strains of Enteritidis [10], 
eight strains of Dublin [11] and one strain each of six other serotypes of Salmonella of O serogroup D [11] were also examined (Table 1). Strains were grown in LB broth or on LB agar, as described before [10, 11].

\section{Isolation of DNA}

Total DNA was isolated by a neutral SDS method [4]. For PFGE a more gentle method was used to ensure isolation of DNA of high mol.wt [12].

\section{Restriction endonuclease digestion}

Digestions with restriction endonucleases were carried out as recommended by the suppliers (Boehringer Mannheim or Amersham). Pst I and $P v u$ II were used for IS200 typing, SmaI for ribotyping and NotI for PFGE.

\section{Agarose gel electrophoresis (AGE)}

Digestion fragments of total DNA for IS200 typing and ribotyping were separated by electrophoresis overnight at low voltage $(2 \mathrm{~V} / \mathrm{cm})$ through agarose $0.8 \% \mathrm{w} / \mathrm{v}$ gels (Litex LSL) in $1 \times$ TAE buffer [13]. Digoxigeninlabelled phage lambda digested with HindIII (Boehringer Mannheim) was used as a mol.wt marker. For pulsed-field gel electrophoresis (PFGE), DNA digests in agarose plugs (BioRad Chromosomal Grade Agarose) were subjected to PFGE in agarose $1.0 \% \mathrm{w} / \mathrm{v}$ gel in $0.5 \times \mathrm{TBE}$ [13] in a modified contour-clamped homogeneous electric field system (Pulsaphor Plus, Pharmacia). The running conditions have been reported previously [10]. Polymerised phage lambda DNA (Pharmacia) was used as a molecular size marker.

Table 1. Strains of Salmonella examined

\begin{tabular}{lcc}
\hline $\begin{array}{l}\text { Serotype, origin and year } \\
\text { of isolation }\end{array}$ & $\begin{array}{c}\text { Number } \\
\text { of strains }\end{array}$ & Reference \\
\hline Gallinarum, & & 3,4 \\
Denmark, 1948 & 4 & \\
Denmark, 1963 & 2 & \\
Denmark, 1986 & 6 & \\
Greece & 2 & \\
Gambia & 1 & \\
Kenya & 2 & \\
UK & 4 & \\
USA & 3 & \\
Pullorum & 1 & 3,4 \\
Denmark, 1951 & 16 & \\
Denmark, 1981-88 & 4 & \\
Denmark, from pheasants & 2 & \\
UK & 1 & \\
Africa & 10 & 10 \\
Enteritidis* & 8 & 11 \\
Dublin $\dagger$ & 6 & 11 \\
Others in O serogroup D & & \\
\hline
\end{tabular}

${ }^{*}$ Type strain of each of PTs $1-5,10,11,14,18$ and 20.

†One representative each of eight ribotype patterns of Olsen and Skov [11].

$\ddagger$ One strain each of six other serotypes: Daressalaam, Eastbourne, Javiana, Panama, Rostock and S. II 9,12:z39:-.
After electrophoresis, gels were stained in aqueous ethidium bromide (Sigma) $2 \mu \mathrm{g} / \mathrm{ml}$ for $15 \mathrm{~min}$, destained in distilled water for $15 \mathrm{~min}$ and photographed under UV light $(254 \mathrm{~nm})$.

\section{DNA hybridisations}

DNA was transferred from agarose gels to nylon membranes (Hybond-N, Amersham) by vacuum blotting as recommended by the manufacturer (Pharmacia) and fixed by heating for $30 \mathrm{~min}$ at $80^{\circ} \mathrm{C}$. Hybridisations with 11-dUTP-digoxigenin-labelled probes and detection of hybrids were performed as described before [10]. For IS200 typing, the probe was complementary to a 300-bp internal fragment of the insertion element IS200 [14]; for ribotyping the probe was complementary to $16 \mathrm{~S}$ and $23 \mathrm{~S}$ ribosomal RNA of Escherichia coli (Sigma). Hybridisations with the IS200 probe were carried out under conditions of high stringency $\left(6 \times \mathrm{SSC}\right.$ at $\left.65^{\circ} \mathrm{C}\right)$ [13] whereas those with the ribotyping probe were done at low stringency $(6 \times \mathrm{SSC}$ at $56^{\circ} \mathrm{C}$ ).

\section{Similarity of PFGE patterns}

Similarity of PFGE patterns was calculated by means of a computer-based similarity and clustering program (NTSYS version 1.8 from Applied Biostatistics, USA). Dice coefficients were used for similarity calculations and the similarity matrix was expressed graphically by unweighted average linkage (UPGMA). Three similarity matrices were constructed based on input of strains in a randomised order; the same clustering was obtained from each of the matrices.

Plasmids were selectively isolated [3], digested with restriction enzyme NotI and analysed by AGE to show that differences in PFGE patterns were not plasmiddetermined. The scoring of PFGE patterns was based on bands $>100 \mathrm{~kb}$ as no plasmid restriction fragments exceeded this size.

\section{Results}

\section{IS200 patterns}

Three hybridisation patterns, each containing two bands, were observed when strains of serotype Gallinarum of biotypes Gallinarum and Pullorum were hybridised with IS200 (Fig. 1). All but two strains of biotype Gallinarum from Kenya and three strains of biotype Pullorum from Denmark, Africa and the UK showed the same pattern (Table 2), which was also seen with strains of serotype Enteritidis of phage types (PTs) 1, 4 and 5 (data not shown). The IS200 patterns of the remaining strains of group D Salmonella analysed were different. Strains of serotype Dublin and one strain of serotype Rostock showed identical IS200 patterns, as previously reported [11]; the remaining five strains either did not hybridise with 


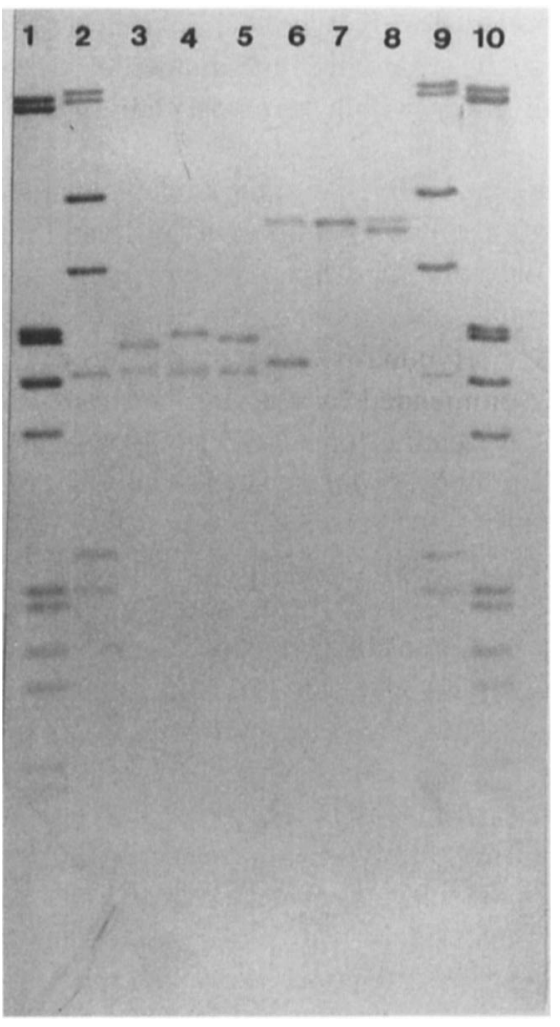

Fig. 1. IS 200 patterns of strains of serotype Gallinarum of biotypes Gallinarum and Pullorum. Mol.-wt markers of phage lambda DNA digested with EcoRI and HindIII or with HindIII are shown (lanes 1, 2, 9, 10). Patterns I, II and III obtained after digestion of DNA with Pst I are shown (lanes 3-5, respectively); the patterns of the same strains after digestion with $P v u$ II are shown (lanes 6-8, respectively).

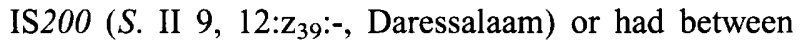
four and seven copies of IS200 in their genome (Eastbourne, Javiana and Panama).

\section{Ribotypes}

The distribution of ribotypes within serotype Gallinarum is summarised in Table 2. All strains of biotype Gallinarum showed the same SmaI ribotype. Strains of biotype Pullorum were of three different ribotypes; the most common type (ribotype II) was seen in 19 of the 24 strains analysed. Of the two remaining types, one (ribotype I) was identical to that observed in all strains of biotype Gallinarum. One isolate from Africa showed a distinct ribotype (ribotype III). The ribotype patterns of serotype Gallinarum are shown in Fig. 2.

The ribotype patterns of serotype Gallinarum were different from those of other group D salmonellae analysed (data not shown). The SmaI ribotypes of serotypes Enteritidis (represented by a strain of PT3) and Dublin (represented by ribotype I according to Olsen and Skov [11]) both shared 9 of 12 ribotype bands with the common types of Gallinarum and Pullorum. The strain of serotype Rostock shared seven bands with these common types and the remaining strains of other serotypes shared four or five bands.

\section{$P F G E$}

Thirteen PFGE profiles were observed among the strains of biotype Gallinarum and 11 other profiles among strains of biotype Pullorum. The patterns differed from those of the other serotypes analysed. Due to the complexity of the PFGE patterns, a statistical method was used to evaluate the similarity between PFGE patterns of strains of biotypes Gallinarum and Pullorum. Based on the similarity matrix, a dendrogram showing two major clusters was produced (Fig. 3). Two clusters ( $a$ and $b$ ) joined at $70 \%$ similarity. Cluster $a$ contained 20 strains of biotype Pullorum and one strain of biotype Gallinarum; cluster $b$ contained the remaining 23 strains of biotype

Table 2. IS 200 patterns, ribotypes and PFGE types of strains of Salmonella of serotype Gallinarum

\begin{tabular}{|c|c|c|c|c|c|c|}
\hline Biotype & $\begin{array}{c}\text { Number of } \\
\text { strains }\end{array}$ & $\begin{array}{l}\text { Country and year } \\
\text { (if known) }\end{array}$ & $\begin{array}{l}\text { IS200 pattern } \\
(P v u \mathrm{II}+P s t \mathrm{I})\end{array}$ & $\begin{array}{l}\text { Ribotype } \\
\text { (SmaI) }\end{array}$ & $\begin{array}{l}\text { Number of } \\
\text { PFGE types } \\
(\text { Not I })\end{array}$ & $\begin{array}{l}\text { PFGE cluster } \\
\text { (see. Fig. 3) }\end{array}$ \\
\hline \multirow[t]{9}{*}{ Gallinarum } & 4 & Denmark, 1948* & I & I & 4 & b \\
\hline & 2 & Denmark, 1963 & I & I & 2 & b \\
\hline & 6 & Denmark, 1986 & I & I & 2 & b \\
\hline & 2 & Greece & I & I & 1 & $\mathrm{~b}$ \\
\hline & 1 & Gambia & I & I & 1 & $\mathrm{~b}$ \\
\hline & 2 & Kenya & II & I & 1 & $\mathrm{~b}$ \\
\hline & 3 & UK & I & I & 3 & b \\
\hline & 1 & UK & I & I & 1 & $\mathrm{a}$ \\
\hline & 3 & USA & I & I & 3 & b \\
\hline \multirow[t]{7}{*}{ Pullorum } & 1 & Denmark, $1951 \dagger$ & III & I & 1 & b \\
\hline & 15 & Denmark, 1981-88 & I & II & 7 & a \\
\hline & 1 & Denmark, 1981-88 & I & I & 1 & a \\
\hline & 4 & Denmark, pheasant, 1984 & I & 11 & 3 & $\mathbf{a}$ \\
\hline & 1 & Africa $\dagger$ & III & III & 1 & Unclustered \\
\hline & 1 & UK $\ddagger$ & I & I & 1 & b \\
\hline & 1 & $\mathrm{UK}+$ & III & I & 1 & Unclustered \\
\hline
\end{tabular}

${ }^{*} \mathrm{H}_{2} \mathrm{~S}$-negative strains 


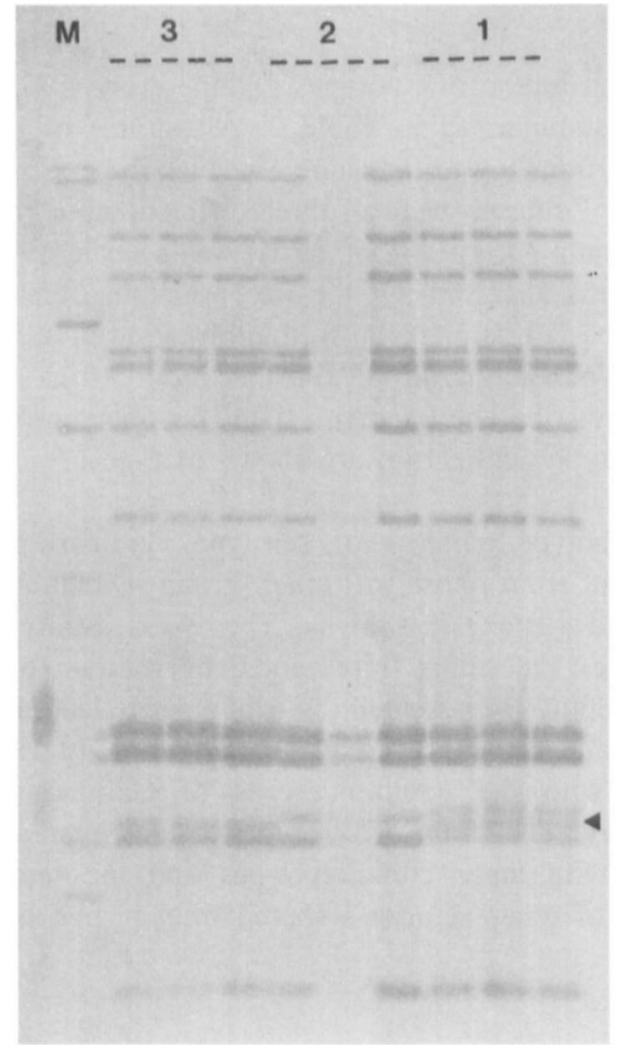

Fig. 2. Sma I ribotypes of strains of serotype Gallinarum of biotypes Gallinarum and Pullorum. Mol.-wt markers of phage lambda DNA digested with HindIII are shown (lane M). Examples are shown of the common ribotype I of Gallinarum strains (lanes marked 3 ), the common ribotype II of Pullorum strains (1) and the unique ribotype III of one Pullorum strain (2). The arrow indicates the area in which differences between ribotypes I-III can be seen.

Gallinarum and two strains of Pullorum; two strains of Pullorum remained unclustered. The clustering according to PFGE is shown in Table 2.

\section{Discussion}

Members of the non-motile $S$. enterica serotype Gallinarum are believed to be closely related and to have shared most of their evolution with another important poultry-associated serotype, Enteritidis [8].

In the present investigation, the close relationship among strains of serotype Gallinarum was indicated by the fact that the same IS200 profile was observed in the majority of strains analysed and irrespective of their biotype. Hybridisation of $P v u$ II- or Pst I-digested chromosomal DNA with a probe of IS200 creates one hybridisation band for each copy of the insertion element [15] and the two copies demonstrated in the present investigation are in accordance with previous reports on copy number in strains of biotype Pullorum $[14,16]$. Strain variation in copy number of IS 200 has been reported for biotype Gallinarum [14] showing that the strains examined may not reflect the range of genetic diversity within serotype Gallinarum.

The three SmaI ribotype patterns demonstrated among strains of serotype Gallinarum differed from each other in only one or two bands, which is less than has been demonstrated among, for example, strains of serotypes Enteritidis [10] and Dublin [11], clearly indicating a close relationship among strains of serotype Gallinarum. Sma I ribotypes have been published previously for serotype Gallinarum, together with EcoR1 and HindIII types [4]. Based on comparison of similarities of patterns from all three enzymes, strains have been reported to form three clusters: one cluster contains strains of biotype Pullorum and two clusters contain strains of biotype Gallinarum. The clusters join at c. $93 \%$ similarity. However, among both biotypes single strains remain unclustered [4]. It has not been investigated how clustering by ribotype agrees with clustering by analysis of isoenzymes nor grouping based on sequence analysis of $f l \mathrm{C}$, as reported by $\mathrm{Li}$ et al. [8]. Such an investigation seems relevant in order to assess the value of ribotype analysis for taxonomic purposes.

PFGE has previously resulted in high discrimination among strains of serotype Gallinarum of biotype Gallinarum [17], as also indicated in the present study by the large number of types observed. In contrast to IS200 patterns and ribotyping, PFGE is believed to measure relatedness over the whole genome, as all restriction sites for the particular restriction endonuclease are included. The graphical presentation of the similarity between the PFGE patterns resulted in the formation of two clusters which remained stable regardless of the order of strain input, indicating that the clustering reflects real genetic similarities.

Each cluster contained the majority of strains of one of the biotypes, as well as one or two strains of the other biotype, indicating a lack of correlation between phenotype and genotype as defined by PFGE. Both strains of biotype Pullorum that clustered with strains of biotype Gallinarum had the same ribotype pattern as strains of biotype Gallinarum, and may resemble strains of Gallinarum at a chromosomal level. One of the strains, which was atypical for biotype Pullorum in being anaerogenic (data from [3]), has been used as a representative of biotype Pullorum in experimental studies of pathogenicity and has been shown to produce typical lesions of Pullorum disease [7]. Thus, the chromosomal markers that have been investigated in the present study are not always good markers for the presence of the, as yet unknown, factors responsible for pathological differences between fowl typhoid and Pullorum disease. The strain of biotype Gallinarum that clustered with the majority of strains of Pullorum by PFGE showed the common IS200 and 

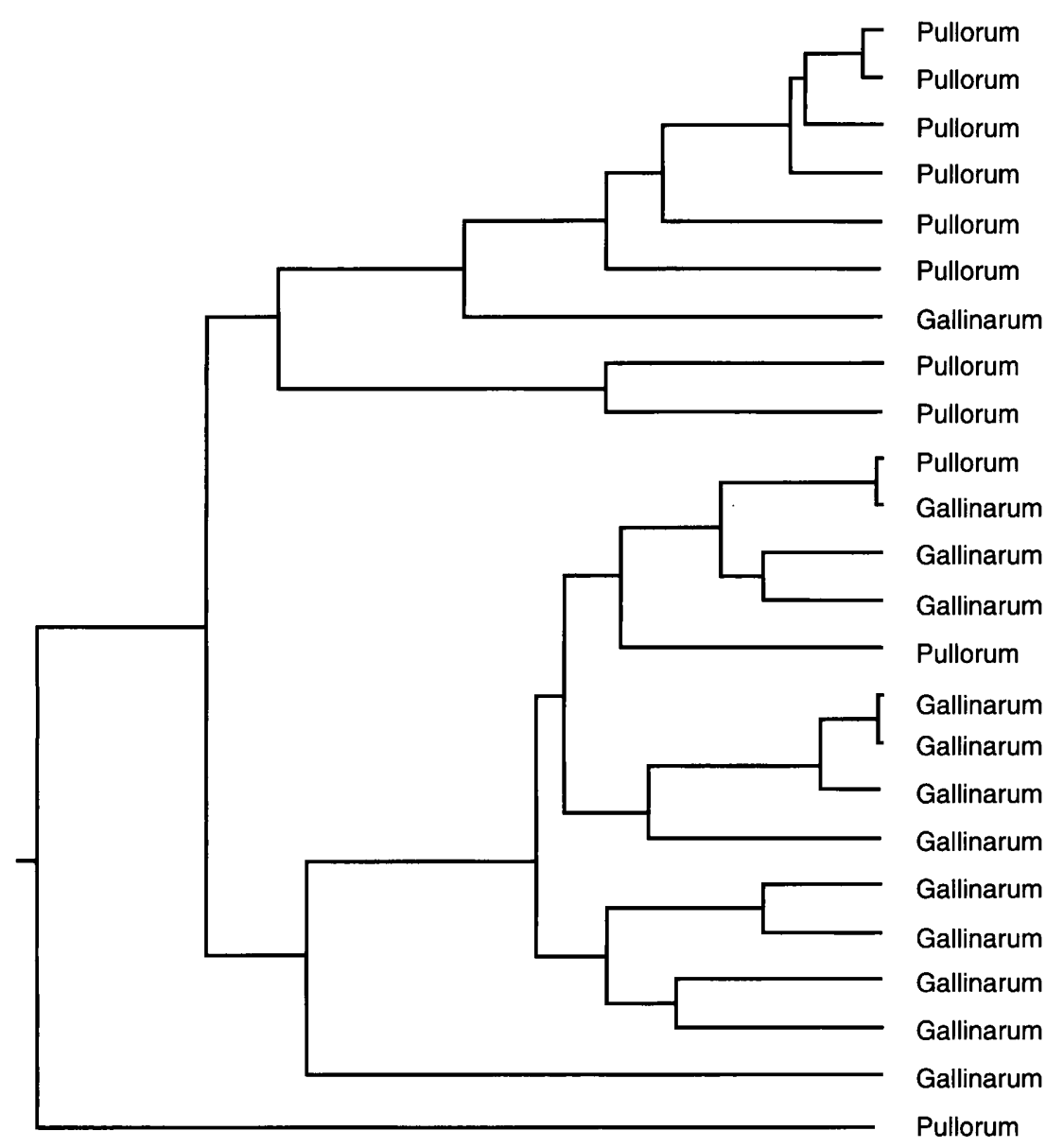

Pullorum

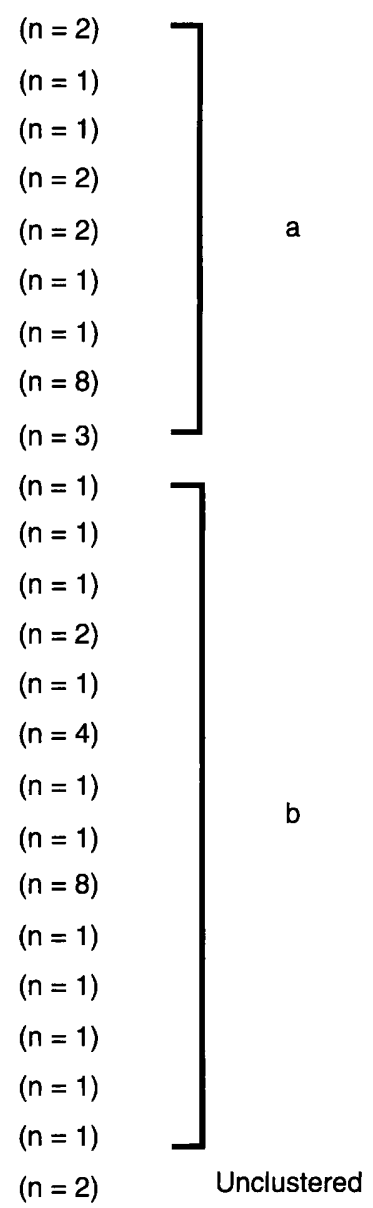

0.7 0.8

Similarity

Fig. 3. Dendrogram showing cluster analysis of strains of serotype Gallinarum of biotypes Gallinarum and Pullorum of PFGE patterns after digestion of DNA with Not $\mathrm{I}$. Two major clusters (a and b) were formed and a small group of. unclustered strains of Pullorum. The number of strains at each position is indicated in parentheses $(n=x)$.

ribotype patterns of biotype Gallinarum and did not show any unusual phenotypic properties when analysed for 74 different characters (see Christensen et al. [3]). It was not possible by the methods used here to explain why this apparently typical strain of serotype Gallinarum biotype Gallinarum shows a larger overall genomic similarity to strains of biotype Pullorum than to those of biotype Gallinarum.

Two strains of Pullorum that remained unclustered by PFGE showed the uncommon IS200 pattern, type III, but were of two different ribotype patterns: one belonged to ribotype I whereas the other showed a unique pattern (III). Both strains are $\mathrm{H}_{2} \mathrm{~S}$ positive [3] and so seem in many respects to represent atypical strains of biotype Pullorum.

The grouping of strains of serotype Gallinarum was different according to the RFLP method used; this is similar to observations made on strains of serotype
Enteritidis [10]. This may result from recombinations taking place between different clonal lines; thus, the RFLP pattern of one line, with a particular marker, may appear in another clonal line. Another possible explanation is that one or more of the RFLP patterns are caused by non-random mutations, in which case the same type may be created during evolution in strains belonging to different clonal lines. Finally, it cannot be excluded that patterns which look similar contain bands that are identical in size but do not contain the same genetic information. However, the majority of strains of biotype Gallinarum always clustered, as did the majority of strains of biotype Pullorum. This shows consistency of the RFLP patterns as well as a high homogeneity between the majority of strains within each biotype. From the present data it may, therefore, be concluded that the two biotypes of serotype Gallinarum seem to be clonal in origin; but it is not possible yet to conclude how the strains of atypical patterns in one or more of the 
typing methods are related in evolutionary terms to the others.

The common IS200 profile in serotype Gallinarum is also commonly observed among representatives of different PTs of serotype Enteritidis [10,15], giving weight to the idea that these two serotypes belong to the same evolutionary line of the genus Salmonella, as suggested by Li et al. [8].

The sequence of $f i \mathrm{C}$ in serotype Dublin is very similar to that in Enteritidis, differing by only three nonsynonymous substitutions in a limited region of the gene [9], and strains from these two serotypes cluster by analysis of isoenzyme profiles $[8,9,18]$. In addition, a subpopulation of serotype Enteritidis shows the same IS200 profile as that seen in all strains of serotype Dublin [11]; the latter serotype may be considered part of the same evolutionary line as serotypes Gallinarum and Enteritidis. In support of this assumption, strains of serotypes Gallinarum, Enteritidis and Dublin share most of the bands in their SmaI ribotype patterns. Based on identity of IS200 patterns between serotypes Dublin and Rostock, and a high similarity between Sma I ribotype patterns of these same serotypes, Rostock is possibly a member of that same evolutionary line, but further analysis is required for confirmation.

Whilst the close relationships between serotypes Enteritidis and Dublin are reflected by both IS200 typing and identity in $16 \mathrm{~S}$ ribotypes [16], strains of Dublin do not show complete identity with strains of serotype Gallinarum in IS200 patterns, 16S ribotype [16] (data published for only one strain of biotype Pullorum) or by $16 \mathrm{~S}+23 \mathrm{~S}$ ribotypes, as in the present investigation. Thus it seems that serotype Enteritidis forms a link in evolutionary terms between serotypes Gallinarum and Dublin.

In conclusion, strains of Salmonella serotype Gallinarum have been shown by three RFLP methods to be closely related and, furthermore, to show the same IS200 pattern as most strains of serotype Enteritidis. The groupings of strains obtained by the three methods were different, but the majority of strains in each of the biotypes Gallinarum and Pullorum, are very similar on a chromosomal level.

This study was supported by the National Agricultural and Veterinary Research Council through grant no. 13-4538-1. The skilful technical assistance of T. Bönnelycke, G. Christensen, A. Forslund, J. Pedersen and $\mathrm{C}$. Rasmussen is acknowledged.

\section{References}

1. von Hinz K-H, Glünder G, Rottmann S, Friederichs M. Über Salmonella gallinarum-Feldisolate der biovare Pullorum und Gallinarum. [Salmonella gallinarum field isolates of the biovars Pullorum and Gallinarum]. Berl Münch Tierärtzl Wochenschr 1989; 102: 205-208.

2. Crichton PB, Old DC. Salmonellae of serotypes Gallinarum and Pullorum grouped by biotyping and fimbrial-gene probing. J Med Microbiol 1990; 32: 145-152.

3. Christensen JP, Olsen JE, Hansen HC, Bisgaard M. Characterization of Salmonella enterica serovar gallinarum biovars gallinarum and pullorum by plasmid profiling and biochemical analysis. Avian Pathol 1992; 21: 461-470.

4. Christensen JP, Olsen JE, Bisgaard M. Ribotypes of Salmonella enterica serovar Gallinarum biovars gallinarum and pullorum. Avian Pathol 1993; 22: 725-738.

5. Blaxland JD, Sojka WJ, Smither AM. A study of Salm. pullorum and Salm. gallinarum strains isolated from field outbreaks of disease. $J$ Comparative Pathol \& Therapeutics 1956; 66: 270-277.

6. Barrow PA, Simpson JM, Lovell MA, Binns MW. Contribution of Salmonella gallinarum large plasmid towards virulence in Fowl typhoid. Infect Immun 1987; 55: 388-392.

7. Barrow PA, Lovell MA. The association between a large molecular mass plasmid and virulence in a strain of Salmonella pullorum. J Gen Microbiol 1988; 134: 2307-2316.

8. Li J, Smith NH, Nelson $\mathrm{K}$ et al. Evolutionary origin and radiation of the avian-adapted non-motile salmonellae. $J \mathrm{Med}$ Microbiol 1993; 38: 129-139.

9. Selander RK, Smith NH, Li J et al. Molecular evolutionary genetics of the cattle-adapted serovar Salmonella dublin. $J$ Bacteriol 1992; 174: 3587-3592.

10. Olsen JE, Skov M, Threlfall EJ, Brown DJ. Clonal lines of Salmonella enterica serotype Enteritidis documented by IS $200-$, ribo-, pulsed-field gel electrophoresis and RFLP typing. J Med Microbiol 1994; 40: 15-22.

11. Olsen JE, Skov M. Genomic lineage of Salmonella enterica serovar Dublin. Vet Microbiol 1994; 40: 271-282.

12. Cameron DN, Khambaty FM, Wachsmuth IK, Tauxe RV, Barrett TJ. Molecular characterization of Vibrio cholerae $\mathrm{O} 1$ strains by pulsed-field gel electrophoresis. J Clin Microbiol 1994: 32; 1685-1690.

13. Maniatis T, Fritsch EF, Sambroke J. Molecular cloning. A laboratory manual. Cold Spring Harbor, NY, Cold Spring Harbor Laboratory. 1982.

14. Gibert I, Barbé J, Casadesús J. Distribution of insertion sequence IS200 in Salmonella and Shigella. J Gen Microbiol 1990; 136: $2555-2560$.

15. Stanley J, Jones CS, Threlfall EJ. Evolutionary lines among Salmonella enteritidis phage types are identified by insertions sequence IS200 distribution. FEMS Microbiol Lett 1991; 82: $83-90$.

16. Stanley J, Powell N, Jones C, Burnens AP. A framework for IS200, 16S rRNA gene and plasmid-profile analysis in Salmonella serogroup D1. J Med Microbiol 1994; 41: 112-119.

17. Christensen JP, Skov MN, Hinz KH, Bisgaard M. Salmonella enterica serovar Gallinarum biovar gallinarum in layers: epidemiological investigations of a recent outbreak in Denmark. Avian Pathol 1994; 23: 489-501.

18. Beltran P, Musser JM, Helmuth $\mathrm{R}$ et al. Toward a population genetic analysis of salmonella: genetic diversity and relationships among strains of serotypes $S$. choleraesuis, $S$. derby, $S$. dublin, $S$. enteritidis, $S$. heidelberg, $S$. infantis, $S$. newport, and S. typhimurium. Proc Natl Acad Sci USA 1988; 85: $7753-7757$. 